\title{
E-laboratory design and implementation for enhanced science, technology and engineering education
}

Uhomoibhi, J., \& Morton, W. (2011). E-laboratory design and implementation for enhanced science, technology and engineering education. Campus-Wide Information Systems, 28(5), 367-377. https://doi.org/10.1108/10650741111181634

Link to publication record in Ulster University Research Portal

\section{Published in:}

Campus-Wide Information Systems

Publication Status:

Published (in print/issue): 01/01/2011

DOI:

10.1108/10650741111181634

\section{Document Version}

Author Accepted version

\section{General rights}

Copyright for the publications made accessible via Ulster University's Research Portal is retained by the author(s) and / or other copyright owners and it is a condition of accessing these publications that users recognise and abide by the legal requirements associated with these rights.

\section{Take down policy}

The Research Portal is Ulster University's institutional repository that provides access to Ulster's research outputs. Every effort has been made to ensure that content in the Research Portal does not infringe any person's rights, or applicable UK laws. If you discover content in the Research Portal that you believe breaches copyright or violates any law, please contact pure-support@ulster.ac.uk. 


\title{
e-Laboratory Design and Implementation for Enhanced Science, Technology and Engineering Education
}

\author{
William Morton and James Uhomoibhi ${ }^{\#}$ \\ School of Engineering, Faculty of Computing and Engineering, University of Ulster, Co Antrim \\ BT37 0QB, Northern Ireland, UK, wj.morton@ulster.ac.uk and j.uhomoibhi@ulster.ac.uk \\ ("author for correspondence)
}

\begin{abstract}
Purpose:

This paper reports on the design and implementation of an e-laboratory for enhanced science, technology and engineering education studies.

\section{Design/Methodology/Approach:}

This paper assesses a computer-based e-laboratory, designed for new entrants to science, technology and engineering programmes of study in further and higher education to enable them complete proper 'hands-on' (not simulation) laboratory experiments off-campus and also in virtual learning environments (VLEs) accessible remotely. The development of such a laboratory was in response to the inherent inability of web-based learning environments to duplicate, off-campus, the laboratory facilities and availability on-campus. The measurement of effectiveness relates to whether a laboratory task can be accurately and completely achieved. Common parameters included percentage task completion, error rate and assistance required. Operations under different conditions were studied and observations made from comparison on implementations.
\end{abstract}

\section{Findings:}

The computer-based e-laboratories deployment, within a specific learning scenario, has been investigated and presented. E-laboratories were found to be more student-centred with learners taking responsibility for their own learning.. The face-to-face (F2F) pre-computer scenario learners had a very low completion rate, a high error rate and required constant assistance. The computer-based scenario resulted in a high completion rate, low error rate and a significant reduction in learner supervision.

\section{Research limitations/implications:}

The technical constraints imposed by present online environments, the resulting impact on specific learning styles, and possible solutions to overcome these limitations are discussed.

\section{Practical Implications:}

Both quantitative surveys and qualitative interviews established a positive impact on student learning, thus justifying development of similar systems. More research and applications could follow as this has the potential to impact positively on development and use of e-labs for enhanced science, technology and engineering studies in terms of costs, time and space requirements.

\section{Originality:}

The recent interest and advances in the development of remote and virtual labs has shown that students of today, who are digital natives, especially those in the fields of science, technology and engineering, finds the use of e-laboratories very useful in enhancing their studies, encouraging them to use familiar technologies to access and do experiments either remotely or virtually online thereby enhancing their learning. The approach adopted is unique and original blending both virtual and hands-on approach to experimental studies.

Keywords: Computer-based e-laboratory, simulation, engineering education, e-learning, learning style.

Paper Type: Innovative Practice 


\section{$1.0 \quad$ INTRODUCTION}

An increasing use is being made of e-learning technologies to widen participation in STEM subjects. Existing systems, however, rely heavily on the exchange of information through text-based formats. Although linguistically intelligent students are very much at home in this environment this may not be so for those having other learning styles and studying approaches. Many students of science, technology and engineering require a more practical approach to study (Kolb, 1984; Honey and Mumford, 1992) and may find their learning needs not being met. Current technologies fail to make available that which is possible on-campus, off-campus. This deficiency is particularly evident to learners who have a preference for a pragmatic hands-on approach to learning.

\subsection{Widening Participation}

E-learning, as defined is a tool, a form of learning that utilises information and communication technologies (ICT) to promote acquisition of knowledge and skills through independent and flexible approaches. This broad definition endorses greater and more innovative exploration into the potential of electronic technologies to support the drive to widen participation (HEFCE, 2009). Many educational institutions participate in this endeavour through the use of virtual learning environments (VLEs). The web-based technology affords anytime availability, of electronically formatted educational materials, to geographically disparate and diverse learner groups over the Internet. Learners have preferences for how they learn, each according to a particular learning style (Kolb, 1984; Honey and Mumford, 1992). Student learning style is important. Kolb's work found that learning style is a determining factor in a learner's field of study and advises that a mismatch between the field's learning norms and the individuals learning style results in people either changing or leaving the field. Research have shown that learning style affects learner performance at university (Marriott, N \& Marriott, P) [4]. It is important that learning materials and environments must accommodate learning style preferences in order to realize the goal of wider online participation (Cornelius, 2000).

Online learning materials should include activities for the different learning styles, so that learners can select appropriate activities based on their preferred styles and online learning must be tailored to appeal to all learning styles to avoid the need for offering a variety of learning methods (Mohamed, 2004; Salmon, 2003). Some others have identified difficulties specific to one learning style (Goldfinch and Hughes, 2007). Referring to the activist learning style of Honey and Mumford, we note that students with a highly activist style are less likely to succeed in first year. The recommendation is that, lecturers should be aware of the potential problems and needs of students with different learning styles, and plan the learning opportunities they provide appropriately. Activist learners, a derivation of Kolb's work, learn best through the concrete experience of doing things (Cornelius, 2000; Pigg, et al, 1980).

\subsection{Existing Virtual Learning Environment Technologies.}

Virtual learning environments (VLEs) provide a wide range of functionality with individual users having access rights tailored to their role. Server-side application software manages programme access and available service with tutorstudent interaction conducted through the Internet connected client-side browsers. Teaching materials exist in a variety of formats such as text, graphics, sound, animation and multimedia. Communication tools, which consists of emails, chat rooms and conference facilities enable collaborative learning through both synchronous and asynchronous mode of engagement. Internet delivered e-learning programmes of study seems to have the potential to move the learning from the classroom to an always-available virtual learning environment.

\subsection{ACTIVE EXPERIMENTATION, INCREASED ENGAGEMENT AND ACTIVE LEARNING.}

Science, technology and engineering students need more than the verbal means of transfer of knowledge through theorybased classroom learning. Learning from experience is the desired learning style for many - Gardner's BodilyKinesthetic and Spatial-Visual, VAK’s Kinesthetic, Kolb’s Converging and Accommodating, and Honey and Mumford's Activists and Pragmatists, are important examples (Kolb, 1984; Honey and Mumford, 1992; Gardner, 1999). Defining learning as the process of creating knowledge through the transformation of experience (Kolb, 1984), we see experience is either through internal reflection (intention), or active external manipulation of the world (extension).

For e-learning programmes to encompass both transformation modalities, requires the addition of functionality to facilitate student involvement in practical learning activities, which permit learning through extension. The provision of active-experimentation, through practical laboratory activity permit learners to learn using their preferred learning style, This has been identified as an essential element in nurturing a positive attitude towards science and engineering, as well as strengthening learner understanding and improving performance within engineering (Ornstein, 2006; Aziz et al, 2007; Aladejana and Aderibigbe, 2007). 
Implementing a programme of courses that encourages knowledge transformation through active-experimentation, in a cost effective way, with existing technologies, is a challenge for e-learning technologists and providers. Blended elearning, that is, combining distance learning with face-to-face modalities, is a possible solution. Running theory based portions of science or engineering courses over the Internet and laboratory segments on-campus is a viable solution. It is however, one that limits the "anywhere anytime” advantages of a fully online programme.

\subsection{Computer-based Simulation}

Computer based simulation is a program that embodies some model aspect of the world. It allows the user to make inputs to the model, runs the model, and displays the result (Laurillard, 1994) They are powerful environments that imitate the real world and have the potential to help learners to understand scientific concepts (Blake and Scanlon, 2007) - Simulation allows students to interact with a computer-based simplified world, where changing experimental parameters permits observation of resulting phenomena. As interaction with a simulated world is managed through the computers' interface devices, the learning event does not duplicate the kinaesthetic, on-campus, active-experimentation required by accommodator and converger learners.

The absence of an opportunity to physically interact, using tactile senses, with the materials and devices used in active-experimentation deprives learners who create knowledge through the transformation of experience, an active learning event oriented to their learning style. This prevents the connection between the learner and real world devices to be made. Devices are seen only as symbols, as flat, two dimensional, graphical representations. A simulated world may enhance reflective learning. However, it does not provide the authenticity inherent in traditional, campus-based, laboratory experiences.

\subsection{Hands-on approach}

Aligning the learning event to the strengths of accommodator and converger learners through direct hands-on experimentation, may be achieved using readily available low cost items. Active experimentation relies on observation to determine the result of the experiment with the human senses; visual, auditory, smell, taste or touch, which is used as the measuring instruments. The learner carries out the experiment by following a sequence of instructions and draws conclusion from observation.

As the complexity of the experiment increases there is an associated need for greater precision of measuring devices - the scaled ruler and weighing scales are examples. Using these basic instruments, learners are able to make judgements on experimental phenomena through active collection and tabulation of data while making reference to theoretical knowledge. When the phenomena are non-observable, for example, electrical energy, or where greater precision is required, then specialist instrumentation is needed. The supply of traditional laboratory instrumentation to support an online course combining active-experimentation and theoretical viewpoints is expensive. Costs, associated with the logistics of deployment, coupled with equipment costs, must be considered. To reduce financial burden a blended learning approach is proposed, where students rely on on-campus laboratory equipment to carry out the applied parts of a course. The need for on-campus support restricts the learner to time and location and diminishes the flexibility normally associated with an e-learning, which seeks to promote flexible and independent approaches.

\subsection{Computer-based Laboratory}

This project took an alternative approach to the development and implementation of a computer-based laboratory. A lowcost, prototype test instrument, exploiting microcontroller technology, was developed to make possible a student-centred, anytime, anywhere, e-laboratory facilitating active-experimentation. Embedding the e-laboratory into an existing VLE was considered counter productive, as this would tie it to a specific VLE, curtail extension to other systems and restrict wider participation. Designing an application that is independent of VLE nuances, but is downloadable, for example as a compressed file, was considered the most suitable approach.

Computer design allows users to add peripheral devices to interact with the system. The measure of voltage levels present on an electronic circuit board requires peripheral hardware specific to that task. The e-laboratory hardware, although controlled by a computer application, is an independent electronic product that sits between the student and the learning environment. It needs to be operationally transparent; users should be able to connect and disconnect hardware in a trouble-free way. If the system is difficult for the learner to use, their involvement in the learning process will be adversely affected and will diminish. Managing application-device communication via a Universal Serial Bus (USB) port achieves this requirement. USB connectivity is considered reliable and is familiar to most computer users. When the correct device driver is installed the operating system recognises the device upon connection and permits communication between the device and the controlling application. The connection and removal of the peripheral device should be problem-free, as desired.

The most part of student interaction is conducted via the user interface of a self-contained computer-based executable application. On double clicking the e-laboratory application icon the application starts. As associated firmware and software is specifically written for each teaching scenario, therefore, essentially, no prerequisites are 
required. The student perceives this interface as the learning environment, interacting as necessary with related instructional materials.

Our initial e-laboratory design has concentrated on its use as a simple test instrument. Unit testing is important to student learning as it provides a means of feedback confirming to the learner their assembled electronic product conforms to its specification. Testing necessitates simultaneous information mapping between complex documents, an assembled electronic circuit board and suitable test instrumentation. The manipulation and visualisation of abstract representations of devices to their real world equivalent, combined with the introduction of unfamiliar laboratory equipment, places a high demand on the learner. Experience would suggest that such demands reduce learner's interest and motivation. Bringing all documents and test instrumentation into a single interface point provides a means to demonstrate to the learner the mapping that exists between these entities.

\section{$2.4 \quad$ Implementation and Use of the e-Laboratory}

Students carried out two test sequences. A screen shot for test sequence 1 is shown below, figure 1 . This test is equivalent in purpose to the traditional implementation where students measure, record and compare onboard voltages at stated test points.

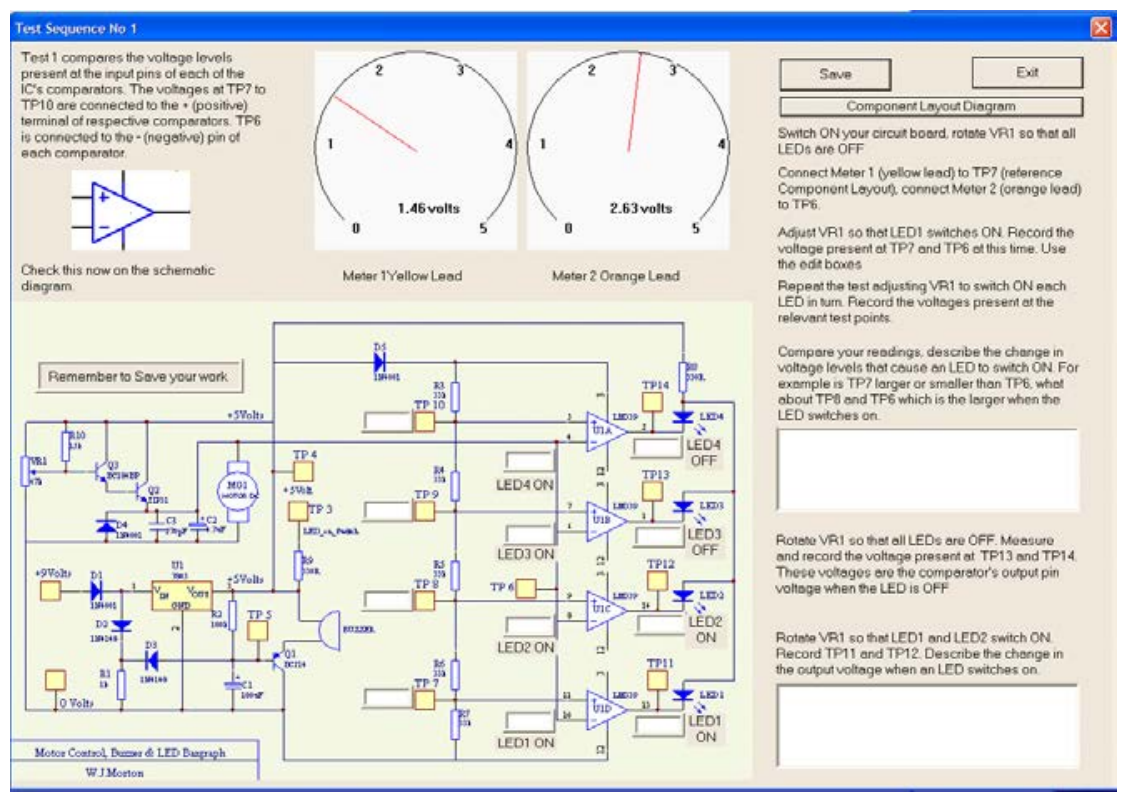

FIGURE 1

TEST SEQUENCE 1DISPLAYING LAYOUT AND VALUES OF PARAMETERS MEASURED.

The top left-hand corner details the purpose of the test. Two voltmeters are included so that comparison can be made between simultaneously taken measurements. Voltmeters are designed to provide a visual and textual display of the voltage reading. The right-hand side of the window has a sequence of tasks for the learner to complete. Edit boxes are placed on the schematic diagram to allow students to input the voltage levels present, as read from the voltmeter, at the associated test point. Using the schematic diagram in this way provides a mapping between the components as laid out on the printed circuit board and the schematic diagram. It is important to note that the readings, as displayed on each voltmeter, are the actual voltage levels present on the circuit board. The test sequence is not a simulation. This is easily observable to the learner through the adjustment of the circuit's variable resistor when a voltmeter lead is connected to the appropriate motor supply voltage test point. When the variable resistor is adjusted, the speed of the motor varies in accordance, and so does the voltage present on the respective voltmeter. A solid connection to real world events, and materials, orientates the learning event to suit those learners who create knowledge through the transformation of experience, the activist and pragmatist.

A screen shot for test sequence 2 is shown in figure 2. The left-hand side of the window displays, as a plotted graph, the change in the voltage level present at a resistor capacitor junction, as a function of time 


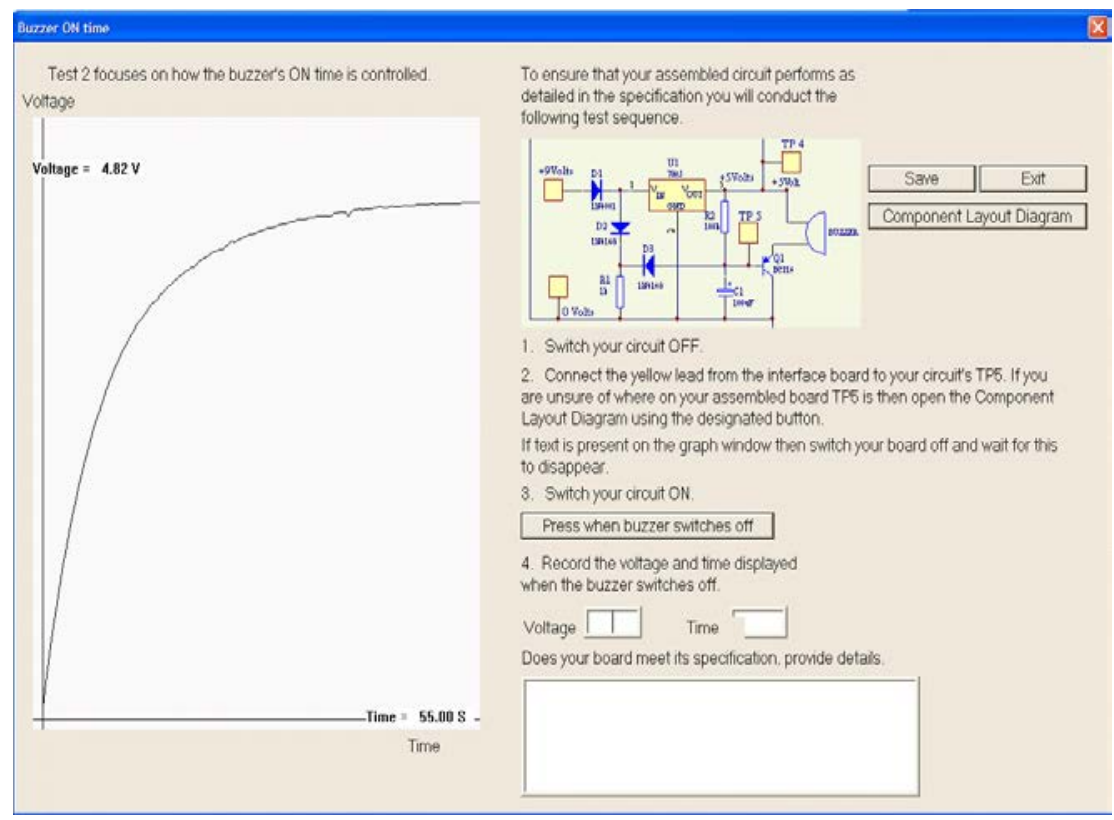

FIGURE 2

TEST SEQUENCE 2 SHOWING LAYOUT AND GRAPH PLOT OF VALUES OF PARAMETERS MEASURED.

over a 55 second period. This graphical example of the charge stored across a capacitor is difficult to observe using a traditional voltmeter. The exercise succinctly connects theory and practice by providing a visually stimulating alternative to textbook examples. Successful completion of both test sequences provides the learner with a means of validation between their assembled board and its specification. Once validation has been achieved the learner is finished with the section of the module.

The firmware code for this project controls the microcontroller's two analogue-to-digital converters. Once programmed, the microcontroller can be used, and will continue to operate under the control of the firmware for as long as it is required, without the need for any further programming. Designed correctly, the interfacing hardware is virtually invisible to the student. The only student interaction required with the element of the system is through a set of conducting leads. These leads electrically connect the interfacing hardware's' analogue-to-digital converters with the voltages present on the student's electronic circuit board.

\subsection{METHODOLOGY}

To evaluate usability, and to validate further development, an action research approach was undertaken. Although envisaged as an off-campus learning environment, downloadable via a VLE, usability evaluation was conducted oncampus in a conventional computer laboratory. This approach allowed observations and comparisons to be made with traditional learning events previously run over a ten year period, in relation to the same learning outcomes. Furthermore, it provided an opportunity to monitor and assist learners while they carried out their tasks. This was beneficial in gaining a better understanding of student requirements and how these could be included in later versions of the software to better assist autonomous learners. In order to establish the level of student satisfaction, a number of questionnaires, comprising three closed and one open sets were used during the study. Questionnaire design was based on the recommendations of Lewis and Cato (Lewis, 1993; Cato, 2000). Informal, unstructured interviews were also used to provide supplementary insights to compliment information obtained using the above mentioned tools.

Questionnaires were incorporated into the learning environment. This approach was taken in order to achieve a closer association between the questions on the questionnaire and the learner's views on the subject being measured. It permitted also the easier management of documentation by saving the result of each questionnaire to a designated file location online, for later opening and processing. The main disadvantage of implementing questionnaires using this format is the disruptive effect on the task activities carried out by learners, which in turn may affect both qualitative and quantitative evaluation measurements (Lewis, 1993).

The sample population consisted of 56 first year undergraduate students enrolled on an Engineering Foundation Degree at the University of Ulster each taking the first year module in Engineering Skills. This cohort was considered ideal for the study as engineers align well to the converger learning style, preferring technical tasks and having a desire to experiment with new ideas (Kolb, 1984). Historically, the cohort is predominately male. However age, gender and ethnicity, for the purpose of the present study have not been considered relevant. Educational background and academic 
achievement are presumed similar. Teaching assumes little or no prior experience in building or testing electronic circuits. Familiarity with the Internet, and interaction with software applications traditionally installed on a home computer, was assumed. Students were informed in writing of the study on the opening page of the e-laboratory and again verbally during each teaching sessions. All learners and participants in the study were assured of the fact that the trial was voluntary.

\subsection{RESULTS}

Of the 56 students registered on the module, 33 completed the printed circuit boards (PCB) assembly stage, with 28 going on to test their circuit. Of these 28 who proceeded, 22 completed the questionnaires. Results indicate that the visual format and structure used for content display was easy to understand. Learners agreed that the activities had practical relevance, were motivating and enjoyable. They found using the e-laboratory improved their understanding of testing methods. The majority of students concluded that the e-laboratory was suitable for distance and online learning incorporating ODL and blended approaches.

Observation of learners in the context of this study, and extensive knowledge of previously run presentations, permitted an accurate subjective assessment to be made on the effectiveness and efficiency of the e-laboratory. Comparing presentations to discover their relative efficiency levels resulted in noticeable differences. During the traditional implementation teaching was tutor-centred with learners depending on tutor support. Computer based provision was found to be more student-centred with learners taking responsibility for their own learning. The measurement of effectiveness relates to whether a task can be accurately and completely achieved (British Standards Institute, 2006). Common parameters included percentage task completion, error rate and assistance required. Obvious differences occurred when comparing the two implementations. The face-to-face (F2F) pre-computer scenario learners had a very low completion rate, a high error rate and required constant assistance. The computer-based scenario resulted in a high completion rate, low error rate and a significant reduction in learner supervision. The difference could not have been more contrasting.

\subsection{CONCLUSIONS}

It is generally agreed that practical laboratory and workshop activities offer science, technology and engineering students an opportunity to advance their learning through the linking of taught theory to the real world (Laurillard, 1994). The benefits associated with laboratory-based hands-on learning are not easily obtainable through present VLE features to online learners. Online virtual laboratories, reliant on simulation software, have been developed to allow students to conduct simulated versions of scientific experiments (Tejedor et al, 2008). Interaction is through a computer-based user interface that lacks a truly hands-on learning experience. This study has taken an alternative and original approach by developing a system where the learner interacts more fully with the materials and devices associated with their subject, doing and carrying out actions, rather than watching. The successful implementation of a computer-based laboratory that can be downloaded with ease, using presently available VLE file transfer capabilities, to distant learners, achieved an extremely positive and encouraging response. From observations, we conclude that learners became actively involved in the learning process and were more inclined to take responsibility for their own learning, through an inquiry based approach, than was normally seen during traditional presentations. Student feedback confirmed a high level of enjoyment when using the system and indicated an increased level of motivation through this experience. Many of the students believed such a system could be used successfully as a distance learning online laboratory. As campus-based students they expressed their desire to have their own e-laboratory which would allow them to complete laboratory work they had missed on-campus. Findings to-date show there is an appetite for using a computer-based laboratory amongst learners. As an enhancement to established traditional teaching models it provides a means of widening participation through diversity of learning stimuli. Current research has been limited to one well defined teaching scenario, however, analysis of gathered data would indicate a wider potential for this type of learning tool in other modules and in other areas of science, technology and engineering fields of study. We recommend that further works be done to extend this piece of research investigation and for the diverse learners in various institutions. The results could spell progress for developments and refinements of works in the development of experiments in these subjects areas carried out in remote and virtual laboratories.

Opportunities exist for the development of a much wider range of interactive teaching materials. For example transducers that respond to variations in environmental phenomenon like pressure, temperature, velocity etc make it possible to set up similar e-laboratories providing endless opportunity to gain knowledge through active-experimentation. Learners would have access to real life data to manipulate and display in an enjoyable but useful way, relating learning to real world occurrences. The world of engineering has always lent itself well to physical learning experiences utilizing laboratory based experiments which have become well established tools for enhanced engineering education, providing support for different learning styles. However these experiments are governed by resources and infrastructure available at a particular institution. This limits exposure of valuable educational material to a small audience. The advent of virtual laboratories has helped to address this problem as well as providing realistic, multidimensional records which captures 
the physical experiments essential characteristics (Kuester and Hutchinson, 2007). Online learning and experiments in virtual worlds enables students to study experiments in real time with access to such advanced features as slow motion, fast-forward and playback. It provides students with the means to observe, explore, analyse and conceptualise complicated experiments in digital form, enhancing and providing positive hand-on learning experience for the learner.

\subsection{REFERENCES}

Aladejana, F. Aderibigbe, O., Science Laboratory Environment and Academic Performance. Journal Science Educational Technology Vol 16, 2007, pp 500-506

Aziz, E. Esche, S. Chassapis, C., IT-Enhanced Laboratory Experience within a Modern Undergraduate Engineering Curriculum. International Conference of Engineering Education, ICEE 2007

Blake, C. \& Scanlon, E., Reconsidering simulations in science education at a distance: features of effective use. Journal of Computer Assisted Learning, 23, 2007, pp 491-502.

British Standards Institute BS ISO/IEC 25062:2006 Software engineering - Software product Quality Requirements and Evaluation (SQuaRE) - Common Industry Format (CIF) for usability test reports 2006.

Cato, J. User-Centered Web Design. London, Pearson Education Limited, 20001.

Cornelius, Online Tutoring e-Book URL:http://otis.scotcit.ac.uk/onlinebook/, 20001.

Gardner, H., Intelligence Reframed. Multiple Intelligences for the 21 $1^{\text {st }}$ Century. New York, Basic Books, 1999.

Goldfinch, J. \& Hughes, M., Skills, Learning styles and success of first-year undergraduates. Active learning in higher education, Vol 8, No 4, 2007, pp 259-273.

HEFCE, Enhancing learning and teaching through the use of technology. HEFCE 2009/12, 2009.

Honey, P \& Mumford, A., The Manual of Learning Styles. Maidenhead: Peter Honey, 1992.

Kolb, D., Experiential Learning Experience as The Source of Learning and Development. New Jersey, Prentice Hall, 1984.

Kuester F.,Hutchinson T.C. A virtualized laboratory for earthquake engineering education, Computer Applications in Engineering Education, vol. 15, issue 1, 2007, pp 15 - 29

Laurillard, D., Rethinking university teaching. A framework for the effective use of educational technology. London, Routledge, 1994.

Lewis, J IBM Computer Usability Satification Questionnaires: Psychometric Evaluation and Instruction for Use. Technical Report 54.786. IBM Corporation, 1993.

Marriott, N \& Marriott, P., Student Learning Style Preferences and Undergraduate Academic Performance at Two UK Universities. International Journal of Management Education, Vol 3, No 1,2003, pp 4 - 13

Mohamed, A., Foundations of Educational Theory for Online Learning In: Anderson, T. \& Elloumi, F. Theory and Practice of Online Learning. Athabasca, Athabasca University, 2004.

Ornstein, A., The frequency of Hands-On Experimentation and Student Attitudes Toward Science: A Statistically Significant Relation. Journal of Science and Technology, Vol 15, No 3, October,2006, pp 285-297.

Pigg, K. Busch, L. \& Lacy, W., Learning Styles in Adult Education: a Study of County Extension Agents. Adult Education Quarterly, Vol 30, No 4, 1980, pp 233-244

Salmon, G., E-moderating. The Key To Teaching \& Learning OnLine. London, Taylor \& Francis Books Ltd., 2003. 
Tejedor, G. Martinez, M. \& Vidaurre, B. An Online Virtual Laboratory of Electricity. International Journals of Distance Education Technologies, Vol 6, Issue 2, 2008, pp 21-33. 